Article

\title{
Highly Thermal Stable Phenolic Resin Based on Double-Decker-Shaped POSS Nanocomposites for Supercapacitors
}

\author{
Wei-Cheng Chen ${ }^{1}$, Yuan-Tzu Liu ${ }^{1}$ and Shiao-Wei Kuo ${ }^{1,2, * \mathbb{D}}$ \\ 1 Department of Materials and Optoelectronic Science, Center of Crystal Research, National Sun Yat-Sen \\ University, Kaohsiung 80424, Taiwan; chwei566@gmail.com (W.-C.C.); ruby860420@gmail.com (Y.-T.L.) \\ 2 Department of Medicinal and Applied Chemistry, Kaohsiung Medical University, Kaohsiung 807, Taiwan \\ * Correspondence: kuosw@faculty.nsysu.edu.tw; Tel.: +886-7-525-4099
}

Received: 25 August 2020; Accepted: 19 September 2020; Published: 21 September 2020

check for updates

\begin{abstract}
In this study we incorporated various amounts of a double-decker silsesquioxane (DDSQ) into phenolic/DDSQ hybrids, which we prepared from a bifunctionalized phenolic DDSQ derivative (DDSQ-4OH), phenol, and $\mathrm{CH}_{2} \mathrm{O}$ under basic conditions (with DDSQ-4OH itself prepared through hydrosilylation of nadic anhydride with DDSQ and subsequent reaction with 4-aminophenol). We characterized these phenolic/DDSQ hybrids using Fourier transform infrared spectroscopy; ${ }^{1} \mathrm{H},{ }^{13} \mathrm{C}$, and ${ }^{29} \mathrm{Si}$ nuclear magnetic resonance spectroscopy; X-ray photoelectron spectroscopy (XPS); and thermogravimetric analysis. The thermal decomposition temperature and char yield both increased significantly upon increasing the DDSQ content, with the DDSQ units providing an inorganic protection layer on the phenolic surface, as confirmed through XPS analyses. We obtained carbon/DDSQ hybrids from the phenolic/DDSQ hybrids after thermal curing and calcination at $900{ }^{\circ} \mathrm{C}$; these carbon/DDSQ hybrids displayed electrochemical properties superior to those of previously reported counterparts.
\end{abstract}

Keywords: POSS; phenolic resin; hydrogen bonding; supercapacitors

\section{Introduction}

Compared with inorganic materials, organic polymers usually possess lower moduli and poorer thermal stabilities and mechanical properties. The incorporation of inorganic nanoparticles (NPs) nanotubes, or nanosheets (e.g., clay [1,2]), graphene [3-5], carbon nanotubes [6-8], or polyhedral oligomeric silsesquioxanes (POSS) [9-13] into a polymer matrix is, however, a relatively simple approach toward improving its mechanical and thermal properties.

Phenolic resin is a typical thermosetting resin that has many applications (e.g., in laboratory countertops, adhesives, and coatings) because of its structural integrity and solvent-resistance. Nevertheless, phenolic resin has been neglected as a material for use in polymer nanocomposites because it has a three-dimensional structure even when it is not crosslinked. Several approaches have been developed, however, to overcome this problem to enhance thermal stability [14-25]. For example, phenolic nanocomposites have been synthesized through intercalative polymerization in organic-modified clays [14] and through sol-gel reactions [15,16]. In addition, the ability of POSS to improve the thermal properties of phenolic resin have been discussed widely [17-25]. Indeed, we have prepared several phenolic/POSS nanocomposites incorporating various functionalized (e.g., isobutyl, acrylate, and acetoxystyrene) POSS NPs, stabilized through hydrogen bonding [17-21]. Zhang et al. incorporated multi-functionalized amine POSS NPs into a phenolic resin, stabilized through hydrogen bonding and covalent crosslinking, to enhance its mechanical properties [22]. Zheng and Liu et al. used 
a multi-functionalized epoxy POSS as a crosslinking agent within phenolic resin, thereby improving its thermal stability [23,24]. Furthermore, we synthesized a multi-functionalized phenol POSS derivative and reacted it with phenol and $\mathrm{CH}_{2} \mathrm{O}$ to obtain various phenolic/POSS hybrids, which also exhibited high thermal stability and low surface energies [25].

Unfortunately, these phenolic/POSS nanocomposites prepared using multi-functionalized POSS NPs have led to insoluble cross-linked phenolic resins [22-25], restricting their applicability. When the POSS NPs presented more than two functional groups, the polymer/POSS nanocomposites formed crosslinked structures, even in the presence of only a small amount of the POSS NPs. Therefore, bifunctionalized POSS NPs, including double-decker silsesquioxane (DDSQ), that can form main-chain-type POSS units have allowed new approaches for the synthesis of novel polymer/POSS hybrids from, for example, polyurethane [26,27], polybenzoxazine [28-30], block copolymer [31,32], and polyimide $[33,34]$ systems.

In this study, we synthesized the bifunctionalized phenolic DDSQ derivative DDSQ-4OH (Scheme 1e) through the hydrosilylation of nadic anhydride (ND) with DDSQ (itself obtained from phenyltrimethylsilane (Scheme 1a) and DD-Na (Scheme 1b), giving DDSQ-ND (Scheme 1d), and subsequent reaction with 4-aminophenol. We then prepared phenolic/DDSQ (PDDSQ) hybrids incorporating various amounts of DDSQ through the reactions of DDSQ-4OH with phenol and $\mathrm{CH}_{2} \mathrm{O}$ under basic conditions (Scheme 1f). Furthermore, we obtained carbon/DDSQ hybrids after thermal curing and calcination of these PDDSQ hybrids; these carbon materials displayed electrochemical properties superior to those of related non-carbonized and even carbonized materials.

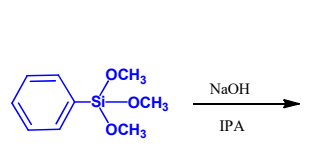

(d)

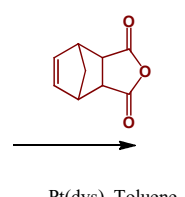

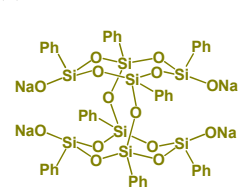

(c)

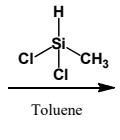

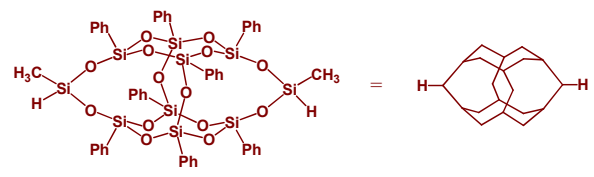

(e)

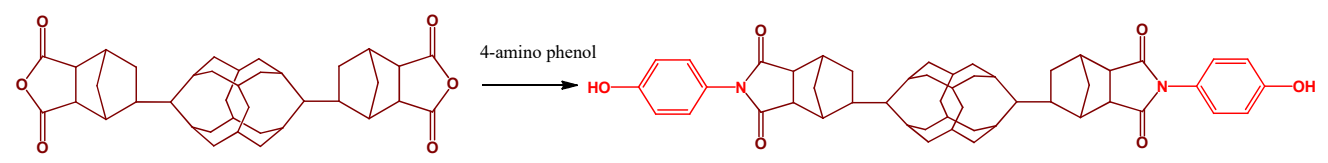

(f)

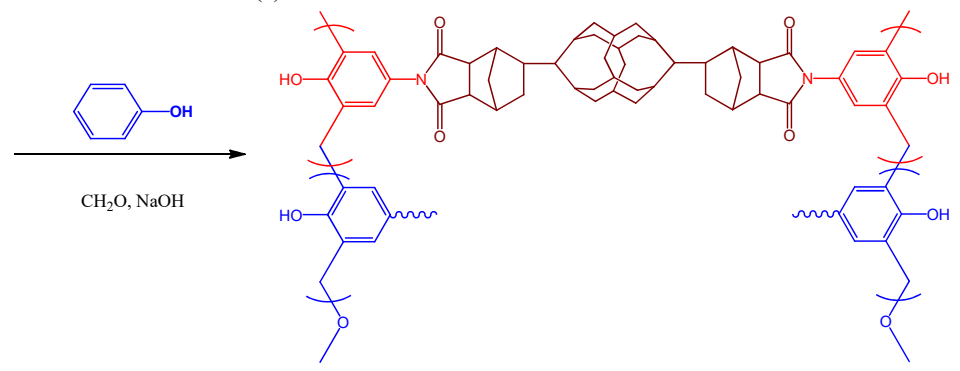

Scheme 1. Chemical structures of (a) phenyltrimethoxysilane, (b) DD-Na, (c) double-decker silsesquioxane (DDSQ), (d) DDSQ-nadic anhydride (ND), and (e) DDSQ-4OH and (f) the preparation of phenolic/DDSQ (PDDSQ) hybrids from DDSQ-4OH and phenol under basic conditions.

\section{Materials and Methods}

\subsection{Materials}

Phenyltrimethoxysilane (Scheme 1a), sodium hydroxide $(\mathrm{NaOH})$, methyl dichlorosilane $\left(\mathrm{CH}_{3} \mathrm{Cl}_{2} \mathrm{SiH}\right)$, charcoal, acetonitrile, $\mathrm{ND}$, paraformaldehyde $\left(\mathrm{CH}_{2} \mathrm{O}\right)$, platinum divinyltetramethyldisiloxane complex 
(Pt (dvs)), 4-aminophenol, and phenol were purchased from Sigma-Aldrich (St. Louis, MO, USA). DDSQ-4OH (Scheme 1e) was synthesized according to a method described previously $[18,35]$.

\subsection{PDDSQ hybrids}

Mixtures of phenol and various amounts of DDSQ-4OH in dioxane and aqueous $\mathrm{NaOH}$ solution were stirred for $10 \mathrm{~min}$; formaldehyde in water was added and then the mixtures were stirred for $10 \mathrm{~min}$ before heating at $70^{\circ} \mathrm{C}$ for $1 \mathrm{~h}$. All compositions of these PDDSQ hybrids used in this study were summarized in Table 1 . The mixture was cooled to room temperature and treated with dilute $\mathrm{HCl}$ solution to $\mathrm{pH}$ 7.0. The water content in the viscous liquid was decreased through distillation under reduced pressure for $2 \mathrm{~h}$ at $45^{\circ} \mathrm{C}$. The resulting PDDSQ hybrids were dissolved in tetrahydrofuran (THF) and stirred vigorously; the precipitated $\mathrm{NaCl}$ was removed through centrifugation.

Table 1. Characterization data for the PDDSQ hybrids synthesized in this study.

\begin{tabular}{|c|c|c|c|c|c|c|c|c|}
\hline \multirow[t]{2}{*}{ Name } & \multicolumn{4}{|c|}{$\begin{array}{l}\text { Monomer Feed } \\
\text { (g) }\end{array}$} & \multirow{2}{*}{$\begin{array}{c}\text { DDSQ-4OH in } \\
\text { hybrids (wt.\%) } \\
\text { FTIR }\end{array}$} & \multirow{2}{*}{$\begin{array}{l}T_{\mathrm{d}} \\
\left({ }^{\circ} \mathrm{C}\right)\end{array}$} & \multirow{2}{*}{$\begin{array}{c}\text { Char Yield } \\
\text { (wt.\%) }\end{array}$} & \multirow{2}{*}{$\begin{array}{c}M_{\mathrm{n}} \\
(\mathrm{g} / \mathrm{mol})\end{array}$} \\
\hline & Phenol & DDSQ-4OH & $\mathrm{CH}_{2} \mathrm{O}$ & $\mathrm{NaOH}$ & & & & \\
\hline $\begin{array}{c}\text { Pure } \\
\text { Phenolic }\end{array}$ & 10.0 & - & 17.25 & 4.25 & 0 & 364 & 41.6 & 5440 \\
\hline PDDSQ-20 & 9.0 & 1.0 & 15.72 & 3.87 & 20.2 & 389 & 47.7 & 4670 \\
\hline PDDSQ-30 & 4.0 & 1.0 & 7.09 & 1.75 & 32.3 & 403 & 49.7 & 4320 \\
\hline PDDSQ-45 & 2.3 & 1.0 & 4.22 & 1.04 & 44.9 & 411 & 55.5 & 4580 \\
\hline PDDSQ-50 & 1.5 & 1.0 & 2.78 & 0.68 & 50.7 & 438 & 58.2 & 4160 \\
\hline PDDSQ-80 & 1.0 & 1.0 & 1.92 & 0.47 & 80.5 & 443 & 63.8 & 4460 \\
\hline Pure PDDSQ & - & 1.0 & 0.19 & 0.04 & 100 & 532 & 70.4 & 4500 \\
\hline
\end{tabular}

\subsection{Carbon/DDSQ Hybrids}

A PDDSQ hybrid was stirred in THF until it had dissolved completely. The solution was poured into a Teflon pan and then the solvent was evaporated at room temperature over 2 days. The resulting solid was heated at $150{ }^{\circ} \mathrm{C}$ for $24 \mathrm{~h}$ to ensure complete thermal curing. Finally, the PDDSQ hybrid was subjected to thermal treatment at $900{ }^{\circ} \mathrm{C}$ for $6 \mathrm{~h}$ under a $\mathrm{N}_{2}$ atmosphere in a tubular furnace to give a carbon/DDSQ hybrid.

\section{Results and Discussion}

\subsection{Synthesis of the Pure PDDSQ Hybrid}

Scheme 1 displays our approach for the synthesis of PDDSQ hybrids featuring various contents of DDSQ; we confirmed their structures using gel permeation chromatography apparatus (GPC, Waters 510, Labx, Midland, ON, Canada) and Fourier transform infrared (FTIR, Nicolet iS50, Thermo Fisher Scientific, Waltham MA, USA) and nuclear magnetic resonance (NMR, Bruker 500, Billerica, MA, USA) spectroscopy. First, we prepared the PDDSQ hybrid from DDSQ-4OH, synthesized as presented in Scheme 1e,f, in the absence of phenol. Figure 1 provides the ${ }^{1} \mathrm{H}$ NMR spectra of DDSQ-4OH and its corresponding pure PDDSQ. The spectrum of DDSQ-4OH (Figure 1a) featured a signal for the $\mathrm{SiCH}_{3}$ unit at $0.36 \mathrm{ppm}$ and signals located between 7.14 and $7.50 \mathrm{ppm}$ representing the aromatic protons of the DDSQ unit. Furthermore, signals from the aliphatic protons of the ND units appeared between 3.25 and $0.83 \mathrm{ppm}$, a broad signal appeared at $5.33 \mathrm{ppm}$ for the $\mathrm{OH}$ units, and signals for the aromatic protons derived from 4-aminophenol appeared at $6.24(l)$ and $6.80(k) \mathrm{ppm}$, confirming the formation of DDSQ-4OH. The ${ }^{1} \mathrm{H}$ NMR spectrum of the pure PDDSQ (Figure 1b) featured small signals at 5.30 and $9.73 \mathrm{ppm}$, representing its aliphatic and phenolic $\mathrm{OH}$ units, respectively. The spectrum of the pure PDDSQ also contained signals from various kinds of $\mathrm{CH}_{2}$ units: $\mathrm{ArCH}_{2} \mathrm{Ar}$ at $1.83 \mathrm{ppm}$ (peak a), methylene ether ( $\left.\mathrm{PhC} \underline{\mathbf{H}}_{2} \mathrm{OR}\right)$ at $3.73 \mathrm{ppm}$ (peak b), and methylol $\left(\mathrm{OC} \underline{\mathbf{H}}_{2} \mathrm{OH}\right)$ (peak c) at $4.82 \mathrm{ppm}$. Furthermore, the intensity of the signal of the aromatic protons from the 4 -aminophenol 
unit at $6.24 \mathrm{ppm}(l)$ had decreased significantly (Figure S1b), consistent with the formation of those bridging aromatic rings, ether, and methylol units.

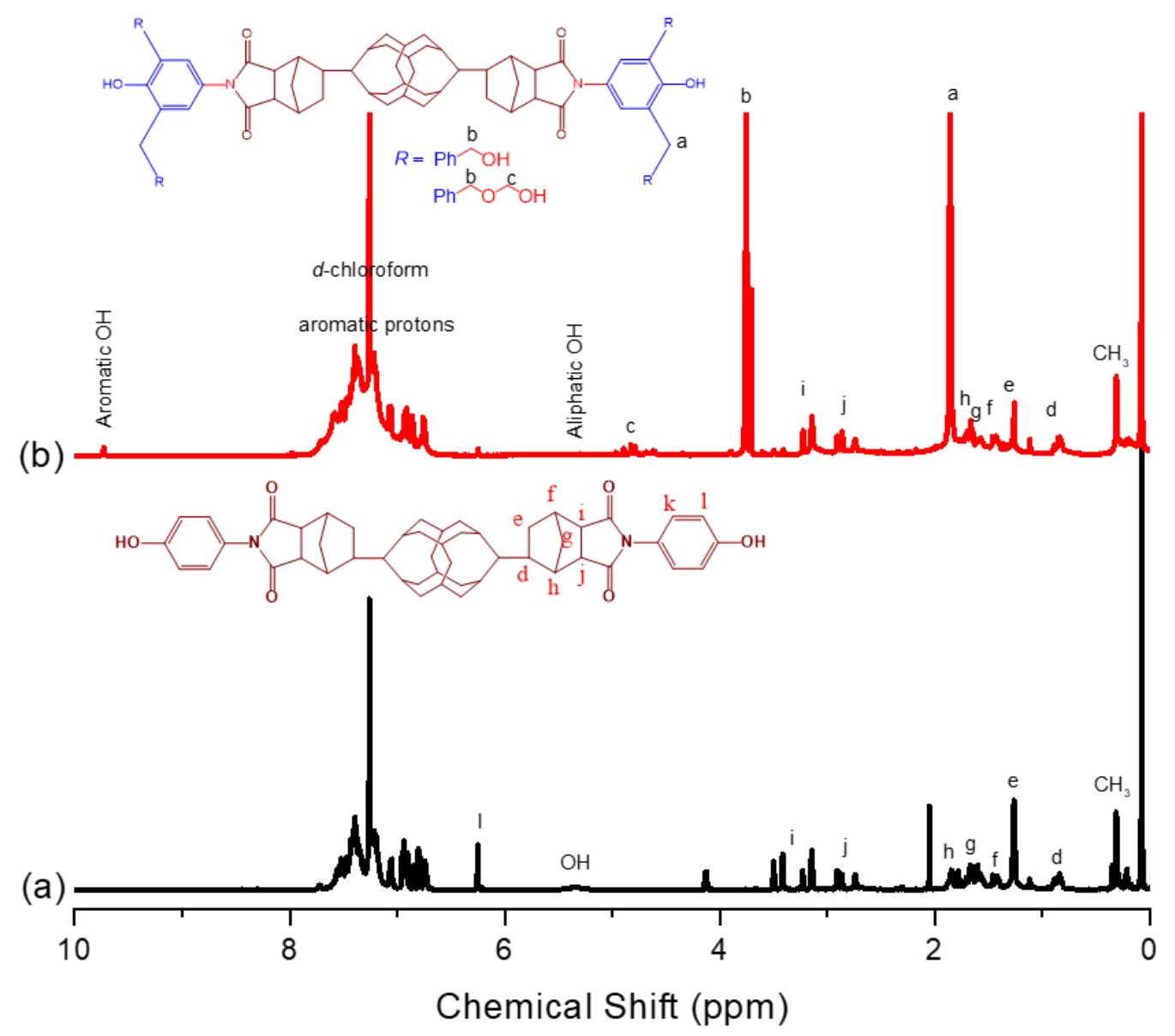

Figure 1. ${ }^{1} \mathrm{H}$ NMR spectra of (a) DDSQ-4OH and (b) pure PDDSQ.

Figure 2 displays the ${ }^{13} \mathrm{C}$ NMR spectra of DDSQ-4OH and its corresponding pure PDDSQ. The spectrum of DDSQ-4OH (Figure 2a) featured a signal for the $\mathrm{SiCH}_{3}$ unit at $0.81 \mathrm{ppm}$, with signals located between 116.3 and $133.0 \mathrm{ppm}$ representing aromatic carbon nuclei. The signals of the aliphatic carbon nuclei of the ND units appeared between 24.5 and $51.3 \mathrm{ppm}$ and those of the aromatic $\mathrm{C}-\mathrm{OH}$ (peak $a$ ) and $\mathrm{C}=\mathrm{O}$ (peak $b$ ) units appeared at 157.3 and $178.8 \mathrm{ppm}$, confirming the formation of DDSQ-4OH. In the spectrum of the pure PDDSQ (Figure 2b), additional peaks appeared at $25.5 \mathrm{ppm}$ for the $\mathrm{ArCH}_{2} \mathrm{Ar}$ (peak c) units and at $68.1 \mathrm{ppm}$ for the methylene ether (peak d) and methylol (peak e) units, along with the other signals from the DDSQ-4OH moieties, confirming the synthesis of the pure PDDSQ.

Figure S1 presents the FTIR spectra of DDSQ-4OH and its corresponding pure PDDSQ. The spectrum of DDSQ-4OH featured two strong signals at 1090 and $1130 \mathrm{~cm}^{-1}$, corresponding to the $\mathrm{Si}-\mathrm{O}-\mathrm{Si}$ and $\mathrm{C}-\mathrm{O}$ units, as well as a signal at $1265 \mathrm{~cm}^{-1}$ representing the $\mathrm{Si}-\mathrm{CH}_{3}$ groups. The spectrum of the pure PDDSQ did not feature any obvious additional peaks when compared with that of DDSQ-4OH, with only the intensity of the signal representing the $\mathrm{OH}$ groups having increased in intensity after the reaction of $\mathrm{CH}_{2} \mathrm{O}$ to form the pure PDDSQ. Figure 3 displays the ${ }^{29} \mathrm{Si} \mathrm{NMR}$ spectra of DDSQ-4OH and the pure PDDSQ. The spectrum of DDSQ-4OH featured three major peaks at $-79.05,-64.17$, and -21.34 ppm representing the $\mathrm{SiO}_{3} \mathrm{R}\left(\mathrm{T}_{3}\right), \mathrm{SiO}_{2} \mathrm{R}_{2}\left(\mathrm{~T}_{2}\right)$, and Si-C units, respectively (Figure 3a). In the spectrum of the pure PDDSQ (Figure 3b), two peaks at -79.05 and $-64.17 \mathrm{ppm}$ were remained, suggesting that the cage structure had not been destroyed; nevertheless, the intensities of these three peaks had decreased, as expected because the concentration of DDSQ units had decreased 
after the formation of the pure PDDSQ. The molecular weight of the pure PDDSQ (ca. $4500 \mathrm{~g} \mathrm{~mol}^{-1}$ ) was determined through GPC analysis, with a polydispersity index of 1.10 (Figure S2).

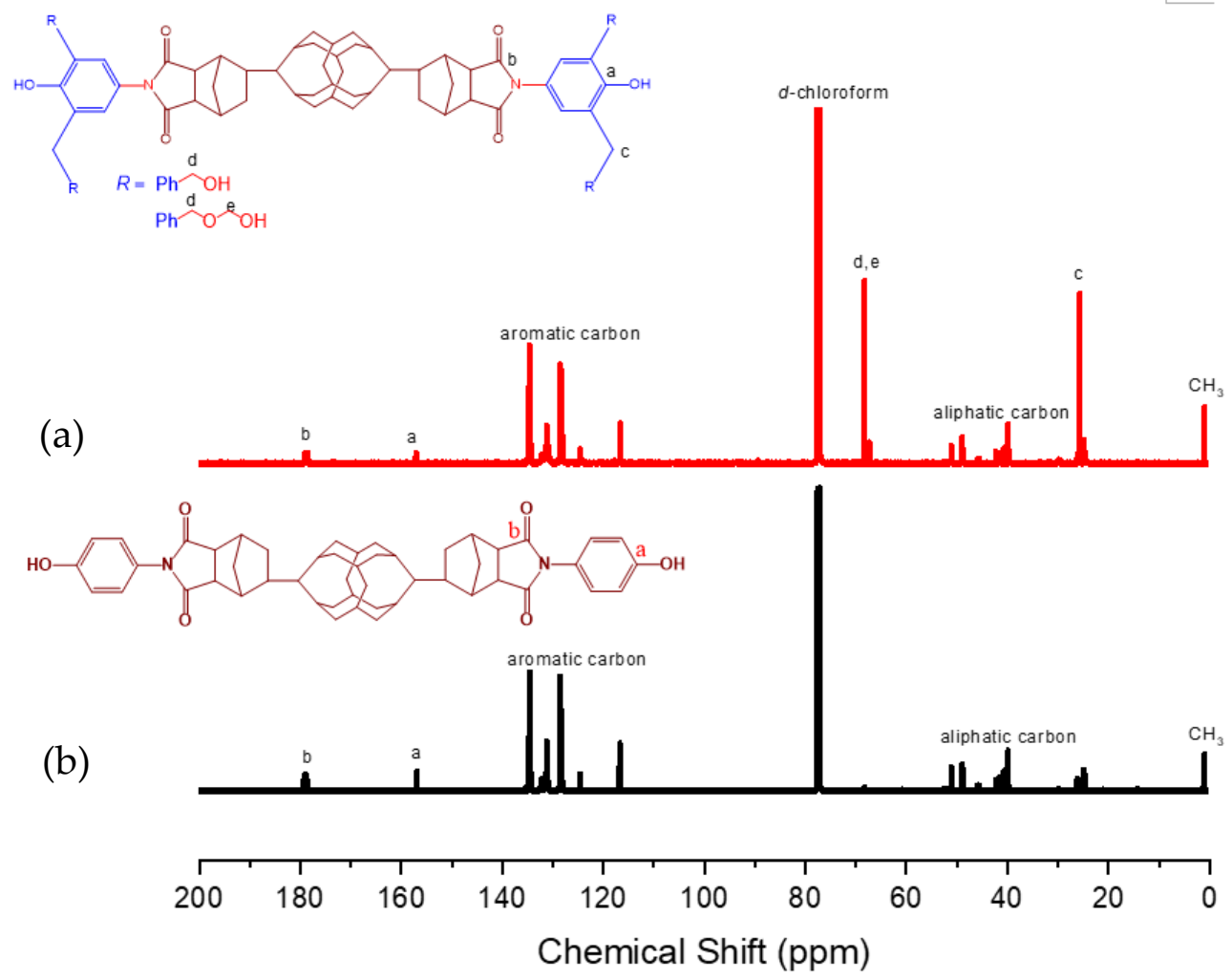

Figure 2. ${ }^{13} \mathrm{C}$ NMR spectra of (a) DDSQ-4OH and (b) pure PDDSQ.

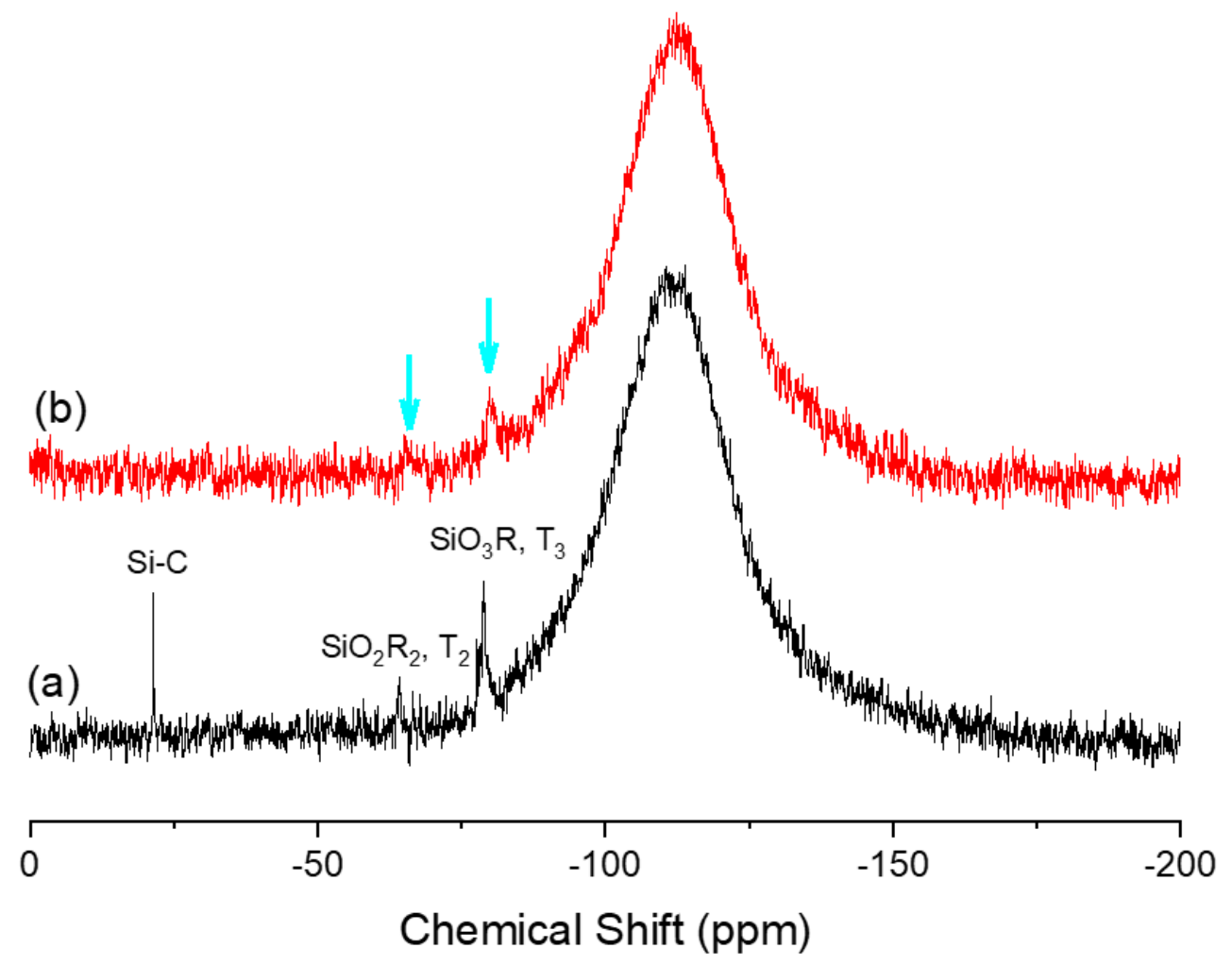

Figure 3. ${ }^{29} \mathrm{Si}$ NMR spectra of (a) DDSQ-4OH and (b) pure PDDSQ. 


\subsection{Synthesis of PDDSQ Hybrids}

Having successfully synthesized the pure PDDSQ, we prepared PDDSQ hybrids incorporating various amounts of DDSQ, as displayed in Scheme 1f. Figure 4 presents FTIR spectra of these PDDSQ hybrids, recorded at room temperature. As mentioned above, the spectrum of the pure PDDSQ featured two strong signals at 1090 and $1265 \mathrm{~cm}^{-1}$ representing the $\mathrm{Si}-\mathrm{O}-\mathrm{Si}$ and $\mathrm{Si}-\mathrm{CH}_{3}$ units of the DDSQ cage structure; in addition, two other obvious peaks appeared at 1702 and $1510 \mathrm{~cm}^{-1}$, representing the $\mathrm{C}=\mathrm{O}$ groups and aromatic units of the $\mathrm{ND}$ and phenolic moieties, respectively. Here, we maintained the signal for the aromatic unit of the phenolic unit at $1510 \mathrm{~cm}^{-1}$, with the intensity of the signal at $1702 \mathrm{~cm}^{-1}$ for the $\mathrm{C}=\mathrm{O}$ groups increasing upon increasing the concentration of DDSQ units in the PDDSQ hybrids. Thus, the composition of DDSQ could be determined readily by the peak ratio $A_{1702} / A_{1510}$ (Table 1). Furthermore, the spectrum of the pure phenolic resin displayed two major signals at 3375 and $3525 \mathrm{~cm}^{-1}$, corresponding to self-associated and free $\mathrm{OH}$ units, respectively. The intensity of the signal for the free $\mathrm{OH}$ units at $3525 \mathrm{~cm}^{-1}$ decreased upon increasing the DDSQ content in the PDDSQ hybrids from 20 to $100 \mathrm{wt} \%$. The signal for the self-association of the phenolic $\mathrm{OH}$ units shifted to higher frequency upon increasing the concentration of DDSQ units in the PDDSQ hybrids, with the peak shifting to $3435 \mathrm{~cm}^{-1}$ as a result of the self-associative $\mathrm{OH}$... OH bonding transforming into inter-associative $\mathrm{OH} \cdot \cdots$ siloxane bonding. The frequency difference $(\Delta v)$ between the signals for the free and hydrogen-bonded $\mathrm{OH}$ groups can give a rough estimation of the average hydrogen bonding strength [36]. The average strength of the phenolic $\mathrm{OH}$ groups interacting with the DDSQ siloxane moieties $\left(\Delta v=95 \mathrm{~cm}^{-1}\right)$ appeared to be weaker than that for the self-associative $\mathrm{OH} \cdots \mathrm{OH}$ bonding of the pure phenolic resin $\left(\Delta v=150 \mathrm{~cm}^{-1}\right)$. This result is consistent with our previous finding that the inter-association equilibrium constant of phenolic/POSS $\left(K_{\mathrm{A}}=38.7\right)$ is smaller than the self-association equilibrium constant of pure phenolic $\left(K_{\mathrm{B}}=52.3\right)$, based on the Painter-Coleman association model [17,18]. Furthermore, Figure S3 presents ${ }^{1} \mathrm{H}$ spectra of pure phenolic resin, PDDSQ-50 and pure PDDSQ recorded at room temperature. The peak assignment is similar with Figure 1 and we could observe that the PDDSQ hybrids are also synthesized successfully based on NMR and FTIR spectra analyses.

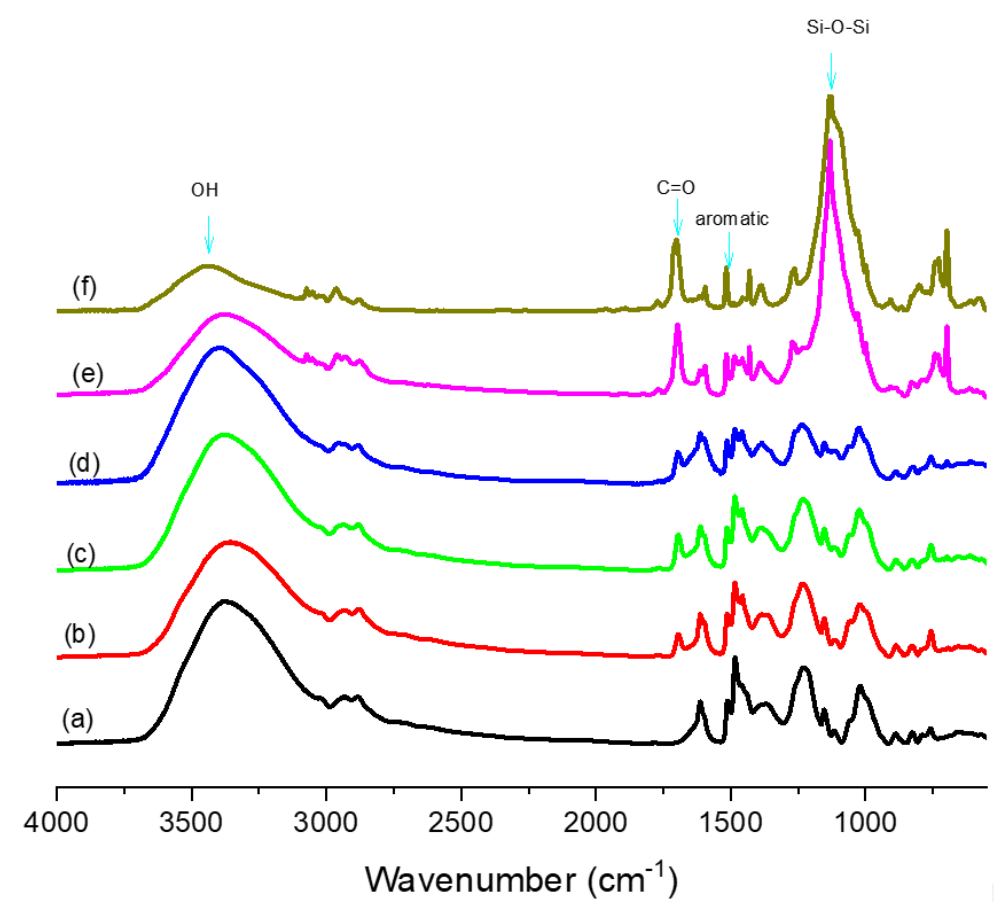

Figure 4. FTIR spectra of (a) pure phenolic, (b) PDDSQ-30, (c) PDDSQ-45, (d) PDDSQ-50, (e) PDDSQ-80, and (f) pure PDDSQ. 
Although we had detected only weak intermolecular interactions between the phenolic $\mathrm{OH}$ groups and the DDSQ siloxane units, these interactions did still enhance the thermal stability of the PDDSQ hybrids, as determined using thermal gravimetric analyzer (TGA, Q-50, TA Instruments, New Castle, DE, USA). The TGA trace (Figure 5) of the pure phenolic resin revealed three thermal degradation steps, typical of the degradation of phenolic resin [37] and the derivative curve was displayed in Figure S4. The first step ca. $250{ }^{\circ} \mathrm{C}$ from the degradation of $\mathrm{CH}_{2}$ bridges, the second step at ca. $450{ }^{\circ} \mathrm{C}$ is due the broken of crosslinking network structure, and the third at ca. $500{ }^{\circ} \mathrm{C}$ comes from the $\mathrm{C}-\mathrm{OH}$ units in phenol were broken and then form $\mathrm{H}_{2}$ gas. Table 1 also summarizes the thermal degradation temperatures $\left(T_{\mathrm{d} 10}\right)$ and char yields at $800{ }^{\circ} \mathrm{C}$ of these PDDSQ hybrids. The char yields and values of $T_{\mathrm{d}}$ increased significantly upon increasing the DDSQ concentration, as expected. For example, the char yield and value of $T_{\mathrm{d}}$ increased by $12.2 \mathrm{wt} \%$ and $79^{\circ} \mathrm{C}$, respectively, for the PDDSQ-80 hybrid when compared with those of the pure phenolic resin. This behavior can be explained by considering the nano-reinforcement effect of incorporating inorganic DDSQ NPs into a phenolic matrix. The DDSQ units were presumably dispersed well within the phenolic resin at the nanoscale, stabilized through hydrogen bonding and covalent bonding, and, thus, they could enhance its initial decomposition temperature. Furthermore, the DDSQ units could retard the thermal motion of the polymer through the covalent bonding, and could also increase the chain spacing, giving rise to the lower thermal conductivity. It has been proposed that DDSQ units prefer to be oriented toward the air side in related nanostructures, because the low surface free energy of the siloxane units would screen out the polar functional units (e.g., carboxyl, $\mathrm{OH}$, and urethane) [38,39]. As a result, we suspect that the DDSQ NPs in our PDDSQ hybrids would also have preferred to be oriented toward the air side, thereby forming an inorganic silica protection layer on the phenolic surface, resulting in higher thermal stability. To confirm this hypothesis, we used X-ray photoelectron spectroscopy (XPS) to examine the surface behavior of our PDDSQ hybrids (Figure 6). Figure 6a reveals the presence of three major elements: $\mathrm{C}$ atoms at $285.1 \mathrm{eV}$ (Figure $6 \mathrm{~b}$ ), $\mathrm{Si}$ atoms at $103.6 \mathrm{eV}$ (Figure $6 \mathrm{c}$ ), and $\mathrm{O}$ atoms at $533.2 \mathrm{eV}$ (Figure 6d). Large amounts of $\mathrm{Si}(20.0 \mathrm{wt} \%)$ and $\mathrm{O}(33.8 \mathrm{wt} \%)$ atoms were present at the surface, indicating that the DDSQ units had to migrated to the surface of the phenolic resin.

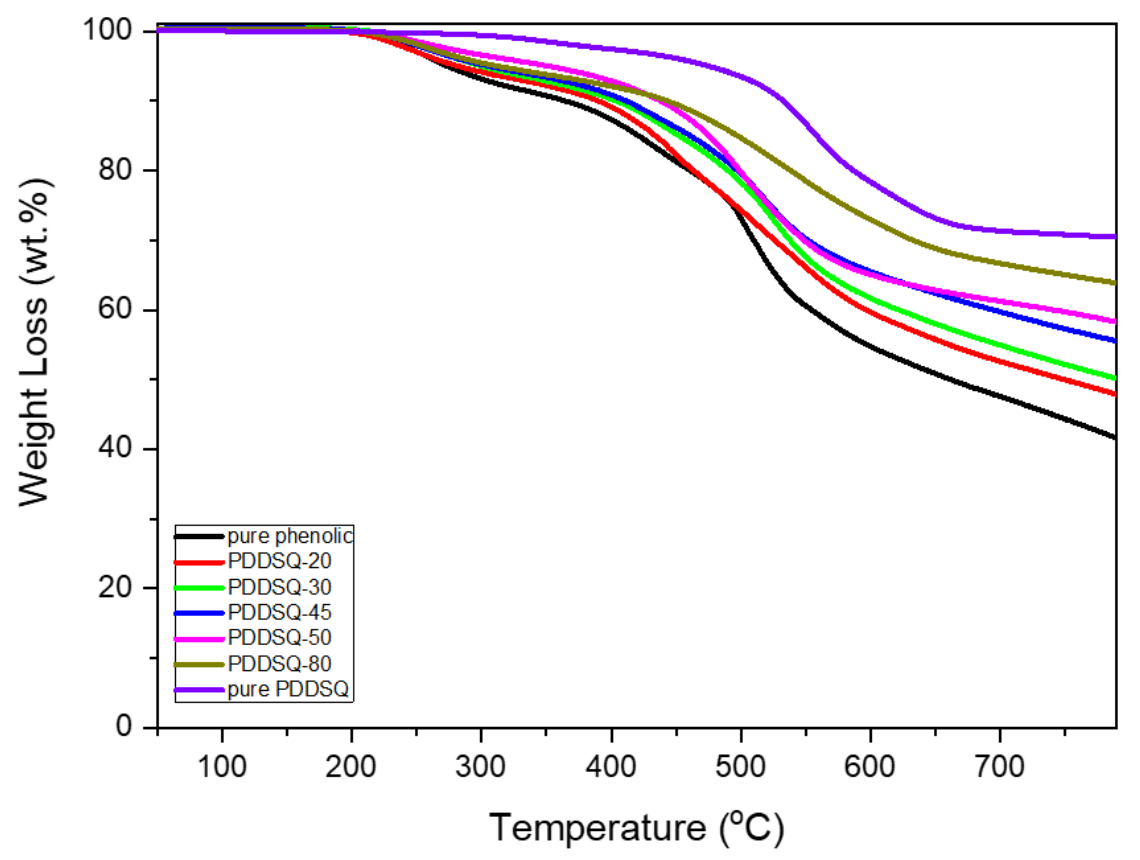

Figure 5. TGA analyses of PDDSQ hybrids containing various DDSQ contents. 

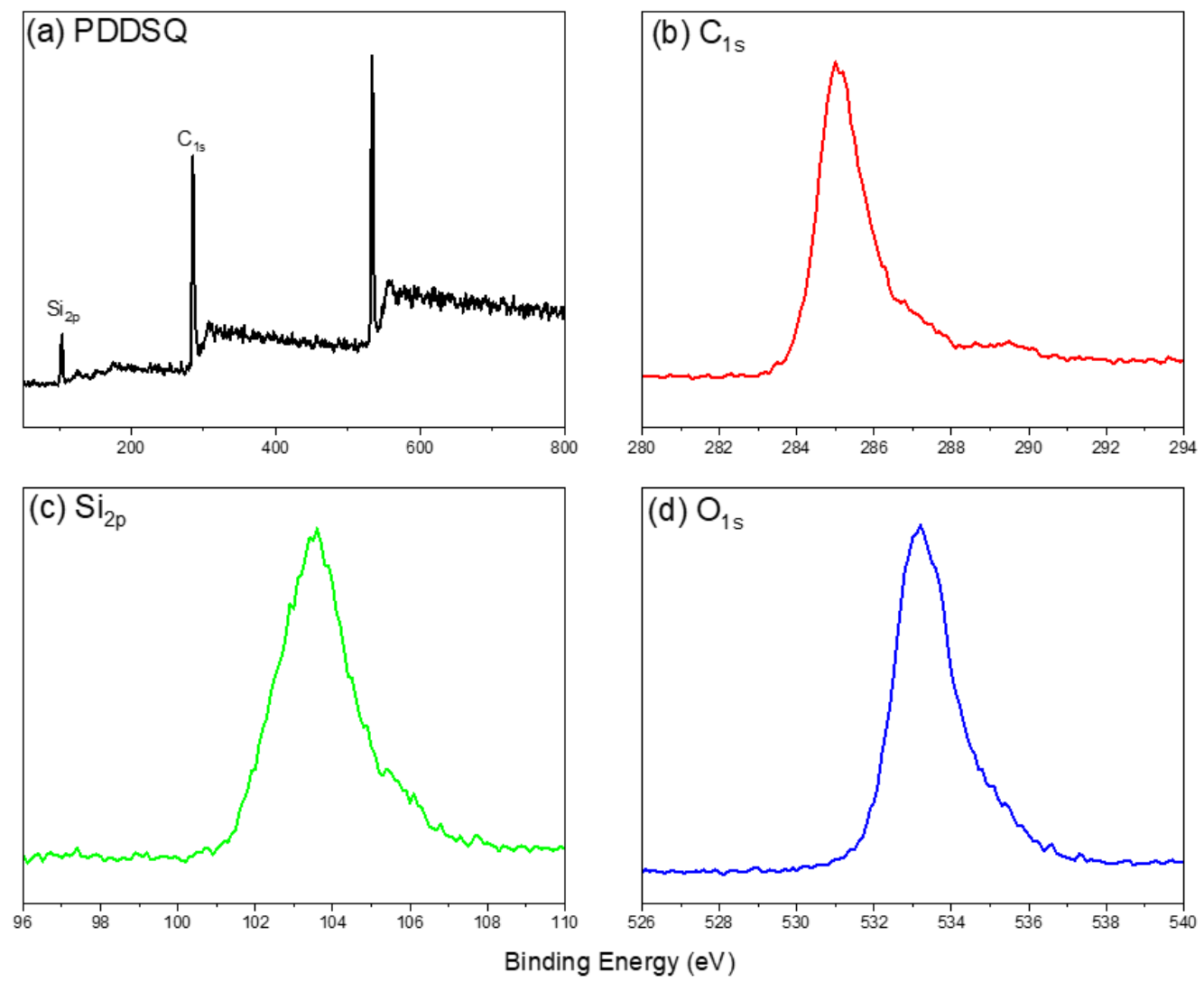

Figure 6. XPS analysis of (a) pure PDDSQ and its (b) C 1s, (c) Si 2p, and (d) O 1s atoms.

\subsection{Synthesis of Carbon/DDSQ Hybrids for Electrochemical Applications}

To obtain carbon/DDSQ hybrids with potential electrochemical applications, we heated the PDDSQ hybrids at $150^{\circ} \mathrm{C}$ for $24 \mathrm{~h}$ to complete their thermal curing, and then subjected them to further heating at 900 or $1000^{\circ} \mathrm{C}$ for $6 \mathrm{~h}$ under a $\mathrm{N}_{2}$ atmosphere. Figure 7a displays FTIR spectra of the pure PDDSQ before thermal curing, after thermal curing at $150{ }^{\circ} \mathrm{C}$, and after heating at $900{ }^{\circ} \mathrm{C}$ to give its carbon/DDSQ hybrid. We have already discussed the spectrum of the pure PDDSQ (Figure S1); the spectrum of the sample obtained after thermal curing at $150{ }^{\circ} \mathrm{C}$ did not exhibit any major changes in its absorption peak. After thermal heating at $900{ }^{\circ} \mathrm{C}$, however, the signals at $1701 \mathrm{~cm}^{-1}$ for the $\mathrm{C}=\mathrm{O}$ groups and at $1432 \mathrm{~cm}^{-1}$ for the aliphatic $\mathrm{CH}_{2}$ units from the ND moieties both disappeared, and new peaks appeared at 1385 and $1612 \mathrm{~cm}^{-1}$ representing the carbon structure. Most importantly, the signals at $1090 \mathrm{~cm}^{-1}$ for the $\mathrm{Si}-\mathrm{O}-\mathrm{Si}$ units and at $1265 \mathrm{~cm}^{-1}$ for the $\mathrm{Si}-\mathrm{CH}_{3}$ units were still present after thermal heating at $900{ }^{\circ} \mathrm{C}$, suggesting that the DDSQ units remained dispersed within the carbon matrix in the carbon/DDSQ hybrids. Raman spectroscopy (HORIBA Jobin-yvon, T6400, Edison, NJ, USA) revealed the local graphitic structure of this carbon/DDSQ hybrid (Figure 7b), with two major carbonized structures identified by G- and D-bands representing $\mathrm{sp}^{2}$ - and $\mathrm{sp}^{3}$-hybridized carbon atoms at 1592 and $1340 \mathrm{~cm}^{-1}$, respectively [40,41]. The G- and D-bands correspond to first- and second-order Raman scattering, respectively; this G-band had undergone a major shift from the wavenumber of a typical G-band (ca. $1582 \mathrm{~cm}^{-1}$ ), suggesting the presence of oxidized graphene after thermal treatment at $900{ }^{\circ} \mathrm{C}\left(1592 \mathrm{~cm}^{-1}\right)$ or $1000{ }^{\circ} \mathrm{C}\left(1620 \mathrm{~cm}^{-1}\right)$. Furthermore, the intensity ratio $I_{\mathrm{D}} / I_{\mathrm{G}}$ can be used to roughly characterize the degree of graphitization. The $I_{\mathrm{D}} / I_{\mathrm{G}}$ ratio $\left(1.35\right.$ after treatment at $\left.900{ }^{\circ} \mathrm{C}\right)$ decreased significantly to 1.01 after thermal treatment at $1000^{\circ} \mathrm{C}$, indicating a highly defected carbon structure containing $\mathrm{Si}, \mathrm{O}$, and $\mathrm{N}$ atoms in the former system, as confirmed by the Transmission electron microscope (TEM, JEOL, JEM-2100, Akishima, Japan) images in Figure 7c,d. The carbon/DDSQ hybrid after thermal treatment at $900{ }^{\circ} \mathrm{C}$ exhibited an irregular structure (Figure $7 \mathrm{c}$ ), but its interlayer spacing was approximately $0.38 \mathrm{~nm}$ (based on the (002) plane of the carbon structure) in Figure 7d, confirmed 
by its WAXD pattern [42]. After thermal treatment at $1000{ }^{\circ} \mathrm{C}$, the high value of $q$ of $16.52 \mathrm{~nm}^{-1}$ $(d=0.38 \mathrm{~nm})$ was due to the (002) plane of the carbon structure (Figure 7e). Therefore, the carbon/DDSQ hybrids had highly defected structures after thermal treatment at $900{ }^{\circ} \mathrm{C}$; we selected three carbon materials - those prepared from the pure phenolic resin, PDDSQ-50, and the pure PDDSQ - to test their suitability for use as electrode materials in supercapacitors.
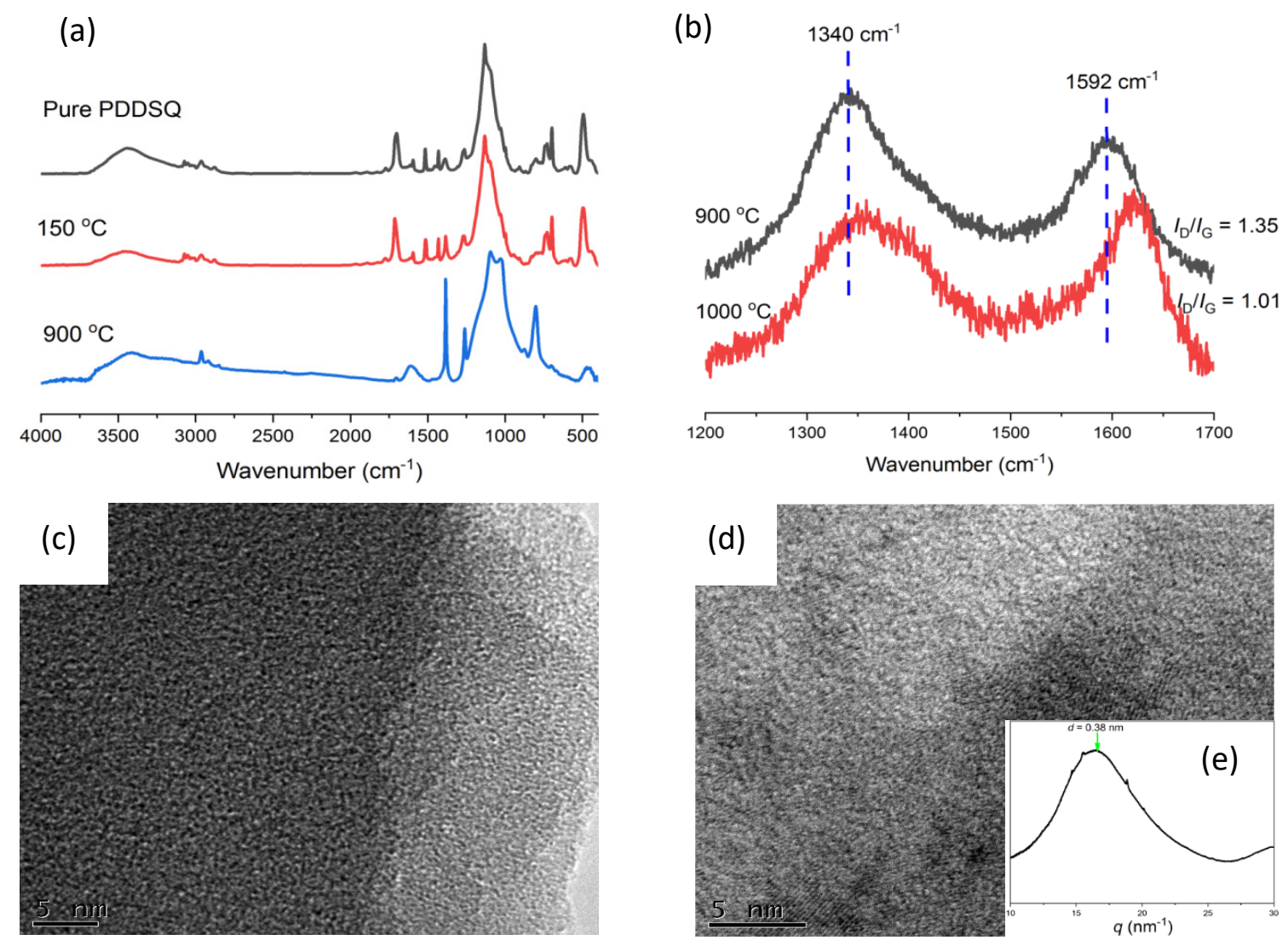

Figure 7. (a) FTIR spectra of pure PDDSQ before thermal treatment and after thermal curing at 150 and $900{ }^{\circ} \mathrm{C}$. (b) Raman spectra of pure PDDSQ after thermal treatment at 900 and $1000{ }^{\circ} \mathrm{C}$. (c,d) TEM images of pure PDDSQ after thermal treatment at (c) 900 and (d) $1000^{\circ} \mathrm{C}$. (e) corresponding WAXD pattern after thermal treatment at $1000{ }^{\circ} \mathrm{C}$.

We used cyclic voltammetry (CV) and the galvanostatic charge/discharge (GCD) method in $1 \mathrm{M} \mathrm{KOH}$ as the aqueous electrolyte in a three-electrode system to investigate the electrochemical performance of our PDDSQ hybrids after thermal treatment at $900{ }^{\circ} \mathrm{C}$. Figure $8 \mathrm{a}-\mathrm{c}$ reveal quite different $\mathrm{CV}$ curves for the carbon/DDSQ hybrids derived from the pure phenolic, PDDSQ-50, and the pure PDDSQ, measured at sweep rates from 5 to $200 \mathrm{mV} \mathrm{s}^{-1}$ in a potential window from +0.35 to $-1.00 \mathrm{~V}$. The most distinct differences appeared at the lowest tested sweep rate of $5 \mathrm{mV} \mathrm{s}^{-1}$ (Figure $8 \mathrm{~d}-\mathrm{f}$ ). The CV curve of the carbon material derived from pure phenolic (Figure 8d) had a rectangle-like shape, implying that its capacitive response resulted from electric double-layer capacitance (EDLC) [43,44]. The CV curve of the carbon material derived from PDDSQ (Figure 8f) had a quasi-rectangular shape featuring a hump, indicating that its capacitive response originated from pseudocapacitance, due to doping by heteroatoms (e.g., $\mathrm{N}$ and and $\mathrm{O}$ atoms), allowing a reversible redox process at the relatively low sweep rate $\left(5 \mathrm{mV} \mathrm{s}^{-1}\right)[45,46]$. A similar phenomenon appeared in the $\mathrm{CV}$ curve of the carbon material derived from PDDSQ-50 (Figure 8e), suggesting a combination of pseudocapacitance and EDLC. Because of the many electroactive centers (e.g., $\mathrm{N}$ and $\mathrm{O}$ atoms and electron-rich phenyl rings) in the carbon material derived from the pure PDDSQ, reversible radical redox procedures occurred during the charging and discharging processes [47]. Furthermore, the current density of the carbon 
material derived from pure PDDSQ increased dramatically upon increasing the sweep rate, while the shape of its CV curve was retained (Figure 8c), indicating good rate capability and facile kinetics [48,49].
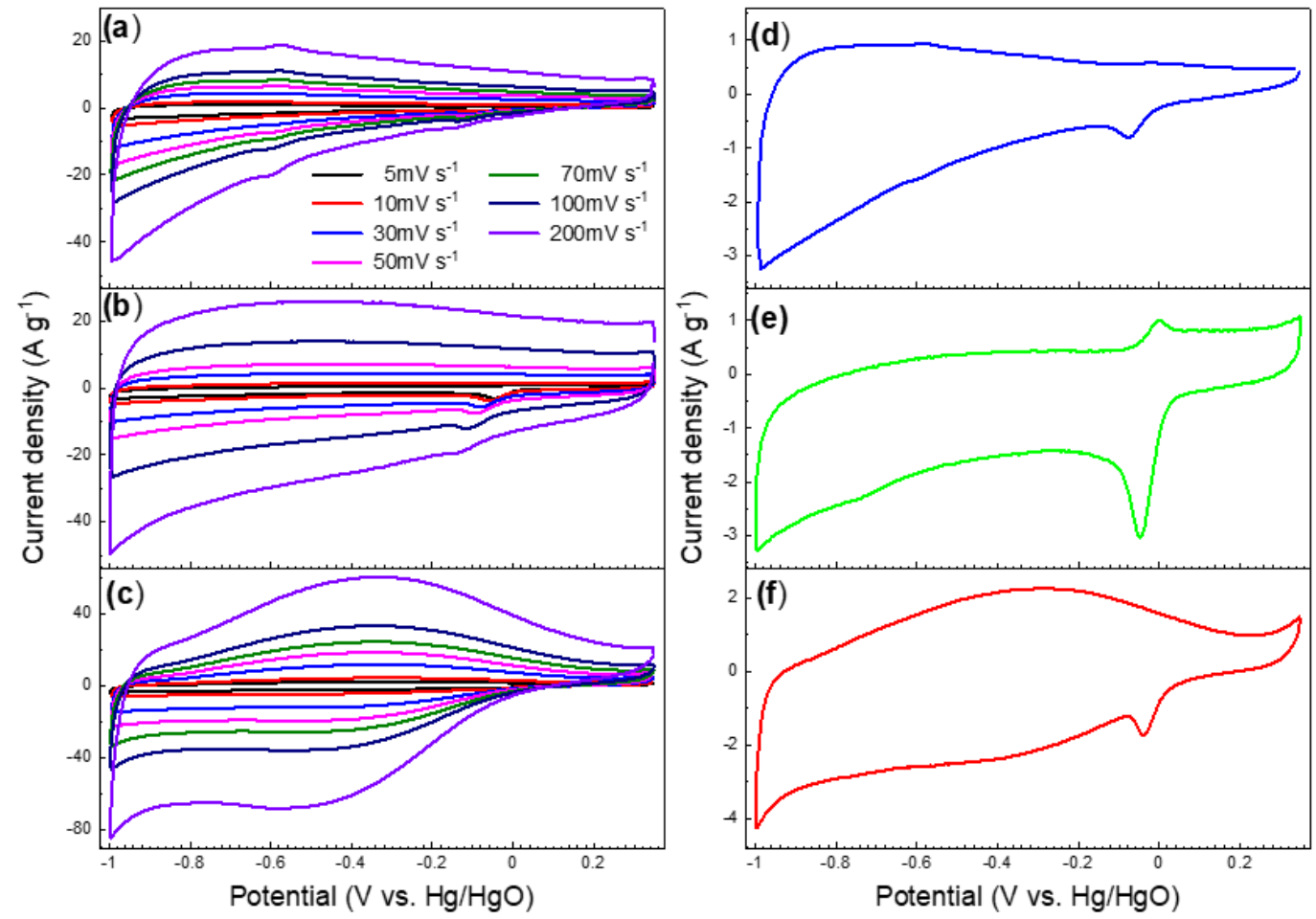

Figure 8. Cyclic voltammetry (CV) curves of carbon/DDSQ hybrids derived from (a,d) pure phenolic, $(\mathbf{b}, \mathbf{e})$ PDDSQ-50, and $(\mathbf{c}, \mathbf{f})$ pure PDDSQ, measured at $(\mathbf{a}-\mathbf{c})$ various scan rates and $(\mathbf{d}-\mathbf{f})$ a scan rate of 5 $\mathrm{mV} \mathrm{s}^{-1}$ in $1 \mathrm{M} \mathrm{KOH}$.

Figure 9 displays the GCD curves of the carbon/DDSQ hybrids derived from pure phenolic, PDDSQ-50, and pure PDDSQ, measured at current densities from 0.5 to $20 \mathrm{~A} \mathrm{~g}^{-1}$. The GCD curves of the carbon material derived from pure phenolic were triangular in shape, suggesting EDLC characteristics, while those of the carbon materials derived from PDDSQ-50 and pure PDDSQ were triangular with a slight bend, implying the presence of both pseudocapacitance and EDLC [49]. The discharging time of the carbon material derived from pure PDDSQ (Figure 9c) was much longer than that of the carbon material derived from pure phenolic (Figure 9a), suggesting that the former capacitance (pure PDDSQ) was larger than that of the latter.

(a)

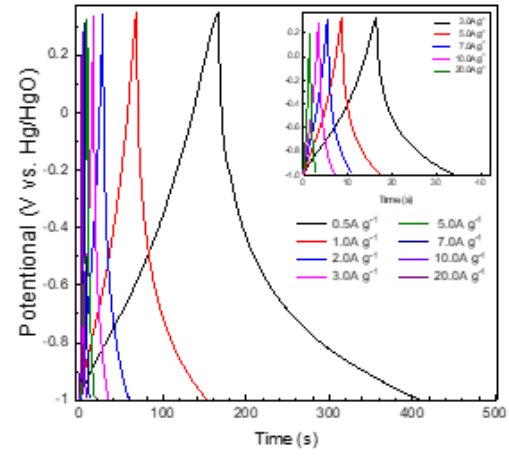

(b)

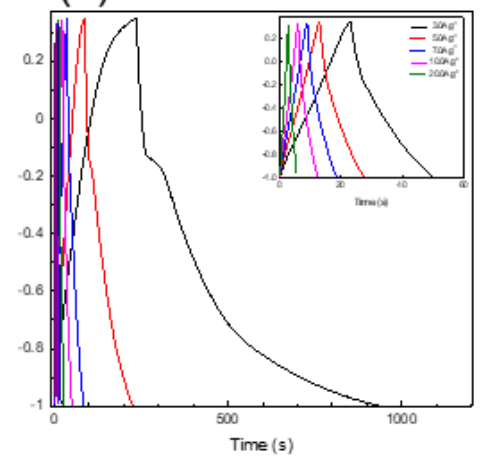

(c)

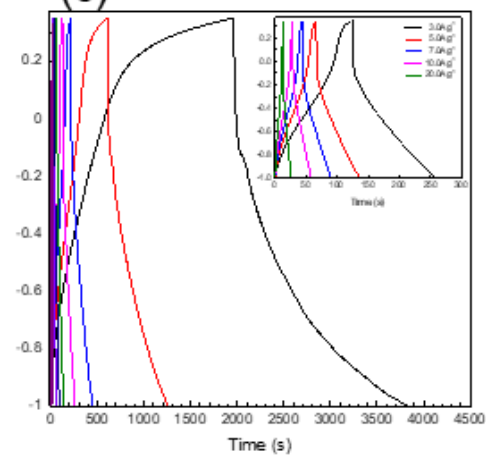

Figure 9. Specific capacitances of carbon/DDSQ hybrids derived from (a) pure phenolic, (b) PDDSQ-50, and (c) pure PDDSQ, measured at various current densities. 
We used Equation S1 to calculate the specific capacitances from the GCD curves (Figure 10). At a current density of $0.5 \mathrm{~A} \mathrm{~g} \mathrm{~g}^{-1}$, the specific capacitance of the carbon material derived from pure PDDSQ $\left(689.5 \mathrm{~F} \mathrm{~g}^{-1}\right)$ was much larger than those of the carbon materials derived from PDDQ-50 (258.8 $\left.\mathrm{F} \mathrm{g}^{-1}\right)$ and pure phenolic $\left(89.9 \mathrm{~F} \mathrm{~g}^{-1}\right)$. The excellent performance of the carbon material derived from pure PDDSQ was due to its many electroactive centers (e.g., $\mathrm{N}$ and $\mathrm{O}$ atoms and electron-rich phenyl rings) making it easier for the electrolyte to access the electrode surface [50]. In addition, the cage structure of DDSQ provided a large number of fine and interlaced channels for the free passage of electrolyte ions. After cycling over 2000 times at $10 \mathrm{~A} \mathrm{~g}^{-1}$, all of the carbon/DDSQ hybrids displayed high cycling stability, retaining over $90 \%$ of their original capacitances (Figure 10b). Although the carbon material derived from pure PDDSQ allowed the electrolyte ions to pass freely, a current density that is too large may cause many thermal effects, resulting in poorer durability. Interestingly, even though the specific capacitance of the carbon material derived from pure phenolic was relatively low, its stability was better than that of the carbon material derived from pure PDDSQ. After cycling the carbon material derived from PDDSQ-50 over 2000 times at $10 \mathrm{~A} \mathrm{~g}^{-1}$, it displayed close to $99.9 \%$ retention; thus, by adjusting the ratios of phenol and DDSQ-4OH during the copolymerization reaction we could balance the electrode materials to obtain both a large specific capacitance and high stability.

(a)

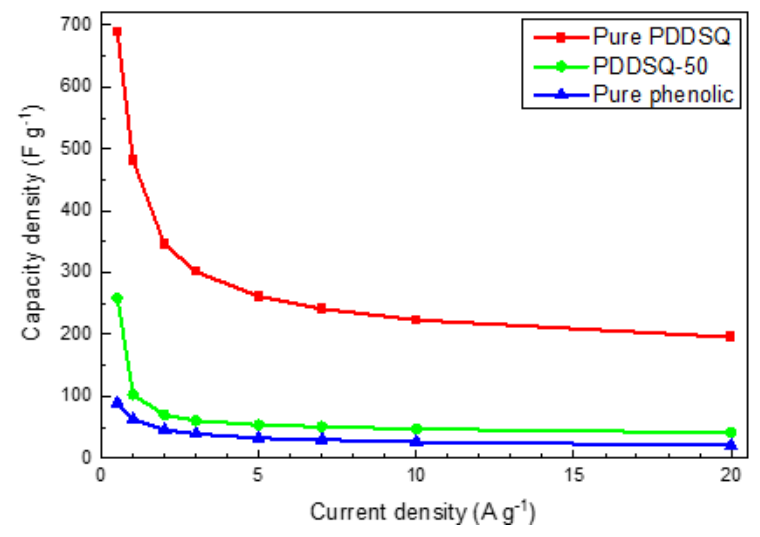

(b)

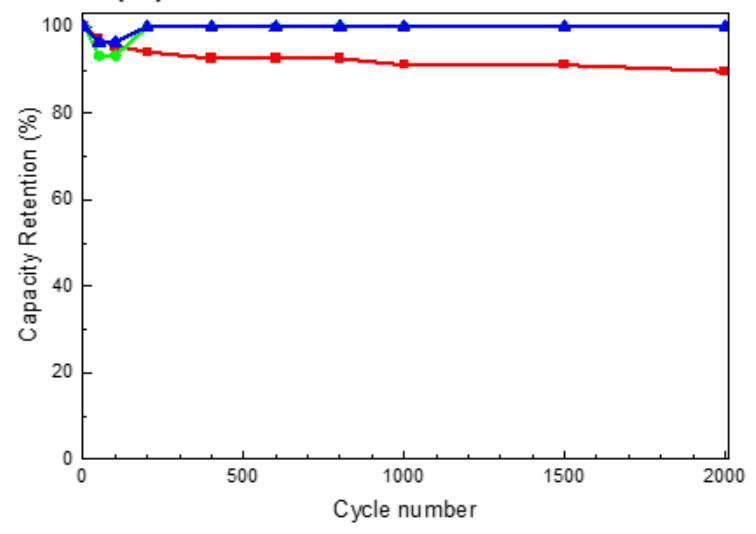

Figure 10. (a) specific capacitances measured at current densities from 0.5 to $10 \mathrm{~A} \mathrm{~g}^{-1}$ and (b) cycling performance measured at a current density of $10 \mathrm{~A} \mathrm{~g}^{-1}$ after 2000 cycles for the carbon/DDSQ hybrids derived from pure phenolic, PDDSQ-50, and pure PDDSQ.

Figure 11 displays the specific energy plotted with respect to the specific power. The carbon material derived from pure PDDSQ exhibited a maximum energy density of $174.5 \mathrm{~W} \mathrm{~h} \mathrm{~kg}^{-1}$ at a power density of $337.5 \mathrm{~W} \mathrm{~kg}^{-1}$; its energy density was maintained at $49.5 \mathrm{~W} \mathrm{~h} \mathrm{~kg}^{-1}$ even at a high power density of $13.5 \mathrm{~kW} \mathrm{~kg}^{-1}$. Compared with other materials prepared in previous studies, our present carbon/DDSQ hybrids displayed excellent properties and were much simpler to prepare, suggesting that they have potential for use as future electrode materials [50-61]. 


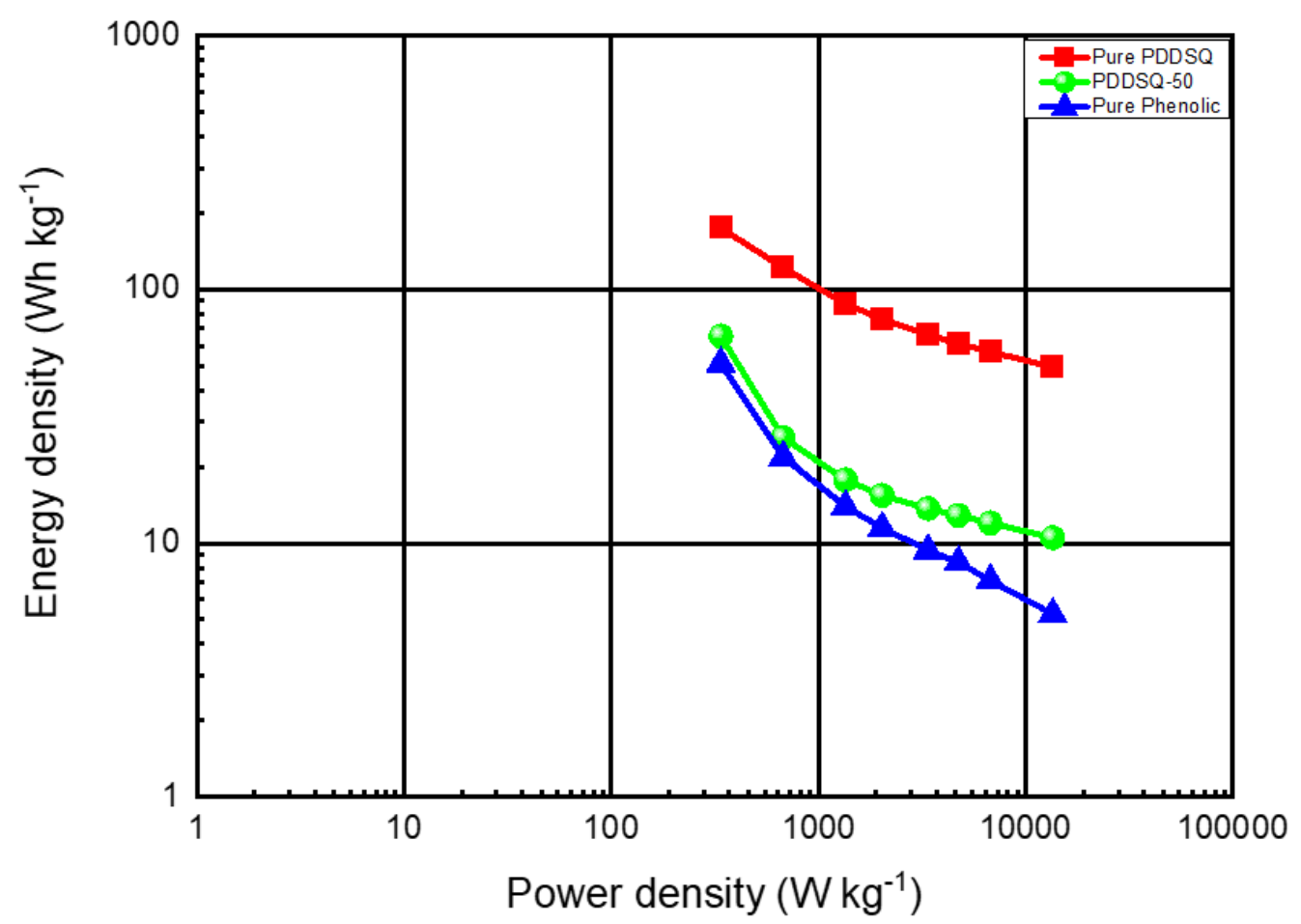

Figure 11. Ragone plots of the energy density and power density of the carbon/DDSQ hybrids derived from pure phenolic, PDDSQ-50, and pure PDDSQ.

\section{Conclusions}

We have synthesized PDDSQ hybrids incorporating various amounts of DDSQ and confirmed their chemical structures using FTIR and NMR spectroscopy. All of these PDDSQ hybrids had char yields and thermal stabilities higher than those of the pure phenolic resin, and they increased upon increasing the DDSQ content in the hybrid systems. The DDSQ units provided an inorganic protection layer on the phenolic surface, as confirmed through XPS analysis. We obtained carbon/DDSQ hybrids after thermal curing and calcination of our PDDSQ hybrids; these carbon materials displayed electrochemical properties superior to those of previously reported counterparts.

Supplementary Materials: The following are available online at http://www.mdpi.com/2073-4360/12/9/2151/s1, Table S1. Comparison between the energy density and power density data/specific capacitance of phenolic/DDSQ hybrids with different materials for supercapacitor application; Figure S1: FTIR spectra of (a) DDSQ-4OH and (b) pure PDDSQ; Figure S2: GPC analysis of pure PDDSQ; Figure S3: ${ }^{1} \mathrm{H}$ NMR spectra of (a) pure phenolic, (b) PDDSQ-50 and (c) pure PDDSQ; Figure S4: TGA analyses of pure phenolic resin and its corresponding derivative curve.

Author Contributions: Data curation, W.-C.C. and Y.-T.L.; Supervision, S.-W.K.; Writing-original draft, S.-W.K.; Writing-review \& editing, S.-W.K. All authors have read and agreed to the published version of the manuscript.

Funding: This research was funded by the Ministry of Science and Technology, Taiwan, under contracts MOST 109-2221-E-110-067-MY3.

Conflicts of Interest: The authors declare no conflict of interest.

\section{References}

1. Chee, S.S.; Jawaid, M. The Effect of Bi-Functionalized MMT on Morphology, Thermal Stability, Dynamic Mechanical, and Tensile Properties of Epoxy/Organoclay Nanocomposites. Polymers 2019, 11, 2012. [CrossRef]

2. Ayat, M.; Rahmouni, A.; Belbachir, M.; Bensaada, N.; Baghdadli, M.C.; Meghabar, R. Thermoplastic block copolymer: Alpha-MethylStyrene and vinyl acetate catalyzed by clay layered called Maghnite- $\mathrm{Na}^{+}$(Algerian MMT). J. Polym. Res. 2019, 26, 230. [CrossRef] 
3. He, J.; Xiao, P.; Liu, W.; Shi, J.; Zhang, L.; Liang, Y.; Pan, C.; Kuo, S.W.; Chen, T. A Universal high accuracy wearable pulse monitoring system via high sensitivity and large linearity graphene pressure sensor. Nano Energy 2019, 59, 422-433. [CrossRef]

4. Diez-Pascual, A.M.; Sanchez, J.A.L.; Capilla, R.P.; Diaz, P.G. Recent Developments in Graphene/Polymer Nanocomposites for Application in Polymer Solar Cells. Polymers 2019, 10, 217. [CrossRef] [PubMed]

5. He, J.; Xiao, P.; Shi, J.; Liang, Y.; Lu, W.; Chen, Y.; Wang, W.; Theato, P.; Kuo, S.W.; Chen, T. High Performance Humidity Fluctuation Sensor for Wearable Devices via a Bioinspired Atomic-Precise Tunable Graphene-Polymer Heterogeneous Sensing Junction. Chem. Mater. 2018, 30, 4343-4354. [CrossRef]

6. Mohamed, M.G.; Kuo, S.W. Functional Silica and Carbon Nanocomposites Based on Polybenzoxazines. Macromol. Chem. Phys. 2019, 220, 1800306. [CrossRef]

7. Kanimozhi, C.; Shea, M.J.; Ko, J.; Wei, W.; Huang, P.S.; Arnold, M.S.; Gopalan, P. Removable Nonconjugated Polymers To Debundle and Disperse Carbon Nanotubes. Macromolecules 2019, 52, 4278-4286. [CrossRef]

8. Zhao, G.X.; Huang, X.B.; Tang, Z.W.; Huang, Q.F.; Niu, F.L.; Wang, X.K. Polymer-based nanocomposites for heavy metal ions removal from aqueous solution: A review. Polym. Chem. 2018, 9, 3562-3582. [CrossRef]

9. Mohamed, M.G.; Kuo, S.W. Polybenzoxazine/Polyhedral Oligomeric Silsesquioxane (POSS) Nanocomposites. Polymers 2016, 8, 225. [CrossRef]

10. Mohamed, M.G.; Kuo, S.W. Functional Polyimide/Polyhedral Oligomeric Silsesquioxane Nanocomposites. Polymers 2019, 11, 26. [CrossRef]

11. Zhang, W.C.; Camino, G.; Yang, R. Polymer/polyhedral oligomeric silsesquioxane (POSS) nanocomposites: An overview of fire retardance. Prog. Polym. Sci. 2017, 67, 77-125. [CrossRef]

12. Chen, W.C.; Lin, R.C.; Tseng, S.M.; Kuo, S.W. Minimizing the Strong Screening Effect of Polyhedral Oligomeric Silsesquioxane Nanoparticles in Hydrogen-Bonded Random Copolymers. Polymers 2018, 10, 303. [CrossRef]

13. Ullah, A.; Shah, S.M.; Hussain, H. Amphiphilic tadpole-shaped POSS-poly(glycerol methacrylate) hybrid polymers: Synthesis and self-assembly. J. Polym. Res. 2019, 26, 4. [CrossRef]

14. Byun, H.Y.; Choi, M.H.; Chung, J. Synthesis and characterization of resol type phenolic resin/layered silicate nanocomposites. Chem. Mater. 2001, 13, 4221-4226. [CrossRef]

15. Ma, C.C.C.; Sung, S.C.; Wang, F.Y.; Chiang, L.Y.; Wang, L.Y.; Chiang, C.L. Thermal, mechanical, and morphological properties of novolac-type phenolic resin blended with fullerenol polyurethane and linear polyurethane. J. Polym. Sci. Polym. Phys. 2001, 39, 2436-2443. [CrossRef]

16. Wei, J.; Wang, G.; Chen, F.; Bai, M.; Liang, Y.; Wang, H.; Zhao, D.; Zhao, Y. Sol-Gel Synthesis of Metal-Phenolic Coordination Spheres and Their Derived Carbon Composites. Angew Chem. Int. Ed. 2018, 130, 9986-9991. [CrossRef]

17. Lee, Y.J.; Kuo, S.W.; Huang, W.J.; Lee, H.Y.; Chang, F.C. Miscibility, specific interactions, and self-assembly behavior of phenolic/polyhedral oligomeric silsesquioxane hybrids. J. Polym. Sci. Polym. Phys. 2004, 42, 1127-1136. [CrossRef]

18. Kuo, S.W.; Lin, H.C.; Huang, W.J.; Huang, C.F.; Chang, F.C. Hydrogen bonding interactions and miscibility between phenolic resin and octa (acetoxystyryl) polyhedral oligomeric silsesquioxane (AS-POSS) nanocomposites. J. Polym. Sci. Polym. Phys. 2006, 44, 673-686. [CrossRef]

19. Chiou, C.W.; Lin, Y.C.; Wang, L.; Hirano, C.; Suzuki, Y.; Hayakawa, T.; Kuo, S.W. Strong Screening Effect of Polyhedral Oligomeric Silsesquioxanes (POSS) Nanoparticles on Hydrogen Bonded Polymer Blends. Polymers 2014, 6, 926-948. [CrossRef]

20. Chiou, C.W.; Lin, Y.C.; Wang, L.; Maeda, R.; Hayakawa, T.; Kuo, S.W. Hydrogen Bond Interactions Mediate Hierarchical Self-Assembly of POSS-Containing Block Copolymers Blended with Phenolic Resin. Macromolecules 2014, 47, 8709-8721. [CrossRef]

21. Yu, C.Y.; Kuo, S.W. Phenolic Functionality of Polyhedral Oligomeric Silsesquioxane Nanoparticles Affects Self-Assembly Supramolecular Structures of Block Copolymer Hybrid Complexes. Ind. Eng. Chem. Res. 2018, 57, 2546-2559. [CrossRef]

22. Zhang, Y.; Lee, S.H.; Mitra, Y.; Kaiwen, L.; Pittman, U., Jr. Phenolic resin-trisilanolphenyl polyhedral oligomeric silsesquioxane POSS hybrid nanocomposites: Structure and properties. Polymer 2006, 47, 2984-2996. [CrossRef]

23. Liu, Y.H.; Zeng, K.; Zheng, S. Organic-inorganic hybrid nanocomposites involving novolac resin and polyhedral oligomeric Silsesquioxane. React. Funct. Polym. 2007, 67, 627-635. [CrossRef]

24. Lei, Z.; Ji, J.; Wu, Q.; Zhang, J.; Wang, Y.; Jing, X.; Liu, Y. Curing behavior and microstructure of epoxy-POSS modified novolac phenolic resin with different substitution degree. Polymer 2019, 178, 121587. [CrossRef] 
25. Lin, H.C.; Kuo, S.W.; Huang, C.F.; Chang, F.C. Thermal and surface properties of phenolic nanocomposites containing octaphenol polyhedral oligomeric silsesquioxane. Macromol. Rapid Commun. 2006, 27, 537-541. [CrossRef]

26. Wei, K.; Wang, L.; Zheng, S. Organic-inorganic polyurethanes with 3,13-dihydroxypropyloctaphenyl double-decker silsesquioxane chain extender. Polym. Chem. 2013, 4, 1491-1501. [CrossRef]

27. Zhao, B.; Wei, K.; Wang, L.; Zheng, S. Poly(hydroxyl urethane)s with Double Decker Silsesquioxanes in the Main Chains: Synthesis, Shape Recovery, and Reprocessing Properties. Macromolecules 2020, 53, 434-444. [CrossRef]

28. Liu, N.; Li, L.; Wang, L.; Zheng, S. Organic-inorganic polybenzoxazine copolymers with double decker silsesquioxanes in the main chains: Synthesis and thermally activated ring-opening polymerization behavior. Polymer 2017, 109, 254-265. [CrossRef]

29. Liao, Y.T.; Lin, Y.C.; Kuo, S.W. Highly Thermally Stable, Transparent, and Flexible Polybenzoxazine Nanocomposites by Combination of Double-Decker-Shaped Polyhedral Silsesquioxanes and Polydimethylsiloxane. Macromolecules 2017, 50, 5739-5747. [CrossRef]

30. Chen, W.C.; Kuo, S.W. Ortho-Imide and Allyl Groups Effect on Highly Thermally Stable Polybenzoxazine/ Double-Decker-Shaped Polyhedral Silsesquioxane Hybrids. Macromolecules 2018, 51, 9602-9612. [CrossRef]

31. Zhao, B.; Mei, H.; Liu, N.; Zheng, S. Organic-Inorganic Polycyclooctadienes with Double-Decker Silsesquioxanes in the Main Chains: Synthesis, Self-Healing, and Shape Memory Properties Regulated with Quadruple Hydrogen Bonds. Macromolecules 2020, 53, 7119-7131. [CrossRef]

32. Chen, W.C.; Tsao, Y.H.; Wang, C.F.; Huang, C.F.; Dai, L.; Chen, T.; Kuo, S.W. Main Chain-Type Block Copolymers through Atom Transfer Radical Polymerization from Double-Decker-Shaped Polyhedral Oligomeric Silsesquioxane Hybrids. Polymers 2020, 12, 465. [CrossRef] [PubMed]

33. Wu, S.; Hayakawa, T.; Kikuchi, R.; Grunzinger, S.J.; Kakimoto, M.; Oikawa, H. Synthesis and characterization of semiaromatic polyimides containing POSS in main chain derived from double-decker-shaped silsesquioxane. Macromolecules 2007, 40, 5698-5705. [CrossRef]

34. Wu, S.; Hayakawa, T.; Kakimoto, M.; Oikawa, H. Synthesis and Characterization of Organosoluble Aromatic Polyimides Containing POSS in Main Chain Derived from Double Decker Shaped Silsesquioxane. Macromolecules 2008, 41, 3481-3487. [CrossRef]

35. Chen, W.C.; Ahmed, M.M.M.; Wang, C.F.; Huang, C.F.; Kuo, S.W. Highly thermally stable mesoporous Poly (cyanate ester) featuring double-decker-shaped polyhedral silsesquioxane framework. Polymer 2019, 185, 121940. [CrossRef]

36. Wang, C.F.; Ejeta, D.D.; Wu, J.Y.; Kuo, S.W.; Lin, C.H.; Lai, J.Y. Tuning the Wettability and Surface Free Energy of Poly(vinylphenol) Thin Films by Modulating Hydrogen-Bonding Interactions. Polymers 2020, 12, 523. [CrossRef]

37. Wang, F.Y.; Ma, C.C.M.; Wu, W.J. Kinetic Parameters of Thermal Degradation of Polyethylene Glycol-Toughened Novolac-Type Phenolic Resin. J. Appl. Polym. Sci. 2001, 80, 188-196. [CrossRef]

38. Turri, S.; Levi, M. Structure, dynamic properties, and surface behavior of nanostructured ionomeric polyurethanes from reactive polyhedral oligomeric silsesquioxanes. Macromolecules 2005, 38, 5569-5574. [CrossRef]

39. Turri, S.; Levi, M. Wettability of polyhedral oligomeric silsesquioxane nanostructured polymer surfaces. Macromol. Rapid Commun. 2005, 26, 1233-1236. [CrossRef]

40. Mohamed, G.M.; Hung, W.S.; EL-Mahdy, A.F.M.; Ahmed, M.M.M.; Dai, L.; Chen, T.; Kuo, S.W. High-Molecular-Weight PLA-b-PEO-b-PLA Triblock Copolymer Templated Large Mesoporous Carbons for Supercapacitors and CO2 Capture. Polymers 2020, 12, 1193. [CrossRef]

41. EL-Mahdy, A.F.M.; Liu, T.E.; Kuo, S.W. Direct synthesis of nitrogen-doped mesoporous carbons from triazine-functionalized resol for CO2 uptake and highly efficient removal of dyes. J. Hazard. Mater. 2020, 391, 122163. [CrossRef] [PubMed]

42. Qu, B.; Li, C.; Zhu, C.; Wang, S.; Zhang, X.; Chen, Y. Growth of MoSe2 nanosheets with small size and expanded spaces of (002) plane on the surfaces of porous $\mathrm{N}$-doped carbon nanotubes for hydrogen production. Nanoscale 2016, 8, 16886-16893. [CrossRef] [PubMed]

43. EL-Mahdy, A.F.M.; Kuo, C.H.; Alshehri, A.A.; Kim, J.; Young, C.; Yamauchi, Y.; Kuo, S.W. Strategic design of triphenylamine-and triphenyltriazine-based two-dimensional covalent organic frameworks for $\mathrm{CO}_{2}$ uptake and energy storage. J. Mater. Chem. A 2018, 6, 19532-19541. [CrossRef] 
44. EL-Mahdy, A.F.M.; Young, C.; Kim, J.; You, J.; Yamauchi, Y.; Kuo, S.W. Hollow Microspherical and Microtubular [3+3] Carbazole-Based Covalent Organic Frameworks and Their Gas and Energy Storage Applications. ACS Appl. Mater. Interfaces 2019, 11, 9343-9354. [CrossRef]

45. Conway, B. Electrochemical Supercapacitors: Scientific Principles and Technological Application; Kluwer Academic/Plenum: New York, NY, USA, 1999.

46. Simon, P.; Gogotsi, Y. Materials for electrochemical capacitors. Nat. Mater. 2008, 7, 845-854. [CrossRef]

47. Su, C.; He, H.; Xu, L.; Zhao, K.; Zheng, C.; Zhang, C. A mesoporous conjugated polymer based on a high free radical density polytriphenylamine derivative: Its preparation and electrochemical performance as a cathode material for Li-ion batteries. J. Mater. Chem. A 2017, 5, 2701-2709. [CrossRef]

48. Hu, F.; Wang, J.; Hu, S.; Li, L.; Shao, W.; Qiu, J.; Lei, Z.; Deng, W.; Jiang, X. Engineered Fabrication of Hierarchical Frameworks with Tuned Pore Structure and N,O-Co-Doping for High-Performance Supercapacitors. ACS Appl. Mater. Interfaces 2017, 9, 31940-31949. [CrossRef]

49. Khattak, A.M.; Ghazi, Z.A.; Liang, B.; Khan, N.A.; Iqbal, A.; Li, L.; Tang, Z. A redox-active 2D covalent organic framework with pyridine moieties capable of faradaic energy storage. J. Mater. Chem. A 2016, 4, 16312-16317. [CrossRef]

50. EL-Mahdy, A.F.M.; Hung, Y.H.; Mansoure, T.H.; Yu, H.H.; Chen, T.; Kuo, S.W. A Hollow Microtubular Triazine-and Benzobisoxazole-Based Covalent Organic Framework Presenting Sponge-Like Shells That Functions as a High-Performance Supercapacitor. Chem. Asian J. 2019, 14, 1429-1435. [CrossRef]

51. Hong, M.S.; Lee, S.H.; Kim, S.W. Use of KCl Aqueous Electrolyte for 2V Manganese Oxide/Activated Carbon Hybrid Capacitor. Electrochem. Solid-State Lett. 2002, 5, A227-A230. [CrossRef]

52. Choi, B.G.; Chang, S.-J.; Kang, H.-W.; Park, C.P.; Kim, H.J.; Hong, W.H.; Lee, S.; Huh, Y.S. High Performance of a Solid-State Flexible Asymmetric Supercapacitor based on Graphene Films. Nanoscale 2012, 4, 4983-4988. [CrossRef] [PubMed]

53. Su, F.; Miao, M. Asymmetric Carbon Nanotube- $\mathrm{MnO}_{2}$ Two-Ply Yarn Supercapacitors for Wearable Electronics. Nanotechnology 2014, 25, 135401. [CrossRef]

54. Tang, J.; Salunkhe, R.R.; Liu, J.; Torad, N.L.; Imura, M.; Furukawa, S.; Yamauchi, Y. Thermal Conversion of Core-Shell Metal-Organic Frameworks: A New Method for Selectively. J. Am. Chem. Soc. 2015, 137, 1572-1580. [CrossRef] [PubMed]

55. Chaudhary, M.; Nayak, A.K.; Muhammad, R.; Pradhan, D.; Mohanty, P. Nitrogen-enriched nanoporous polytriazine for high-performance supercapacitor application. ACS Sustainable Chem. Eng. 2018, 6, 5895-5902. [CrossRef]

56. Ai, W.; Zhou, W.; Du, Z.; Du, Y.; Zhang, H.; Jia, X.; Xie, L.; Yi, M.; Yu, T.; Huang, W. Benzoxazole and benzimidazole heterocycle-grafted graphene for high-performance supercapacitor electrodes. J. Mater. Chem. 2012, 22, 23439-23446. [CrossRef]

57. Puthusseri, D.; Aravindan, V.; Mahdavi, S.; Ogale, S. 3D micro-porous conducting carbon beehive by single step polymer carbonization for high performance supercapacitors: The magic of in situ porogen formation. Energy. Environ. Sci. 2014, 7, 728-735. [CrossRef]

58. Mohamed, G.M.; EL-Mahdy, A.F.M.; Takashi, Y.; Kuo, S.W. Ultrastable conductive microporous covalent triazine frameworks based on pyrene moieties provide high-performance $\mathrm{CO}_{2}$ uptake and supercapacitance. New J. Chem. 2020, 44, 8241-8253. [CrossRef]

59. Samy, M.M.; Mohamed, M.G.; Kuo, S.W. Pyrene-functionalized tetraphenylethylene polybenzoxazine for dispersing single-walled carbon nanotubes and energy storage. Compos. Sci. Tech. 2020, 199, 108360. [CrossRef]

60. EL-Mahdy, A.F.M.; Hung, Y.H.; Mansoure, T.H.; Yu, H.H.; Hsu, Y.S.; Wu, K.C.W.; Kuo, S.W. Synthesis of $[3+3]$ bketoenamine-tethered covalent organic frameworks (COFs) for high-performance supercapacitance and $\mathrm{CO}_{2}$ storage. J. Taiwan Inst. Chem. Eng. 2019, 103, 199-208. [CrossRef]

61. Laing, Z.; Liu, H.; Zeng, J.; Zhou, J.; Li, H.; Xia, H. Facile Synthesis of Nitrogen-Doped Microporous Carbon Spheres for High Performance Symmetric Supercapacitors. Nanoscale Res. Lett. 2018, 13, 314. [CrossRef]

(C) 2020 by the authors. Licensee MDPI, Basel, Switzerland. This article is an open access article distributed under the terms and conditions of the Creative Commons Attribution (CC BY) license (http://creativecommons.org/licenses/by/4.0/). 